\title{
Emprego de Moringa Oleifera Lam Na Inibição de Staphylococcus aureus ATCC 25923 Cultivado em Derivado Lácteo Sintético
}

\author{
Carolini Esmeriz da Rosa (I), João Paulo Gomes de Sousa (I), \\ Fernanda Guimarães Jeronimo (I), Ed Carlo Rosa Paiva (I), \\ Jupyracyara Jandyra de Carvalho Barros (I) \\ (I) UFG/RG - UNIVERSIDADE FEDERAL DE GOIÁS, REGIONAL CATALÃO (Av.: Dr. \\ Lamartine P. Avelar, 1120, Bairro: Setor Universitário; Catalão - GO)
}

\section{Resumo}

Extratos vegetais podem agir como bioconservantes e agregar valor nutricional à matriz alimentícia. Dessa forma, o presente trabalho teve como objetivo monitorar a atividade bactericida do extrato de semente de Moringa oleifera Lam. em Staphylococcus aureus ATCC 25923 cultivado em um simulado lácteo. O extrato (1:5) foi filtrado com auxílio de seringas estéreis em unidades filtrantes constituídos de Membrana em Éster Celulose (MEC) com 0,45 $\mu \mathrm{m}$ de porosidade, e acondicionado em frascos estéreis. Alíquotas equivalentes a $50 \mu \mathrm{L}\left(\mathrm{Mo}_{0,05 \%}\right), 100 \mu \mathrm{L}\left(\mathrm{Mo}_{0,10 \%}\right), 150$ $\mu \mathrm{L}\left(\mathrm{Mo}_{0,15 \%}\right)$ e $200 \mu \mathrm{L}\left(\mathrm{Mo}_{0,20 \%}\right)$ desses extratos foram aplicados em um derivado lácteo sintético, elaborado com leite desnatado reconstituído a $12 \%$ e inoculado com $10^{5}$ células de S. aureus ATCC 25923. Esse simulado lácteo foi incubado a $37^{\circ} \mathrm{C}$ durante 120 horas $\left(\mathrm{T}_{0}, \ldots \mathrm{T}_{120}\right)$. Foram realizadas cinco repetições, e para cada ensaio, alíquotas das amostras foram retiradas em períodos intermitentes e analisadas quanto ao número de unidades formadoras de colônia de S. aureus ATCC 25923 por mililitro da amostra (UFC. $\left.\mathrm{mL}^{-1}\right)$. No grupo controle $(\mathrm{Ct})$ foi aplicada apenas a cepa teste. Em T0 não foi observada redução em $\mathrm{Ct}\left(6,33 \pm 4,48 \log\right.$ UFC. $\left.\mathrm{mL}^{-1}\right)$ e $\mathrm{Mo}_{0,05 \%}$ $\left(6,32 \pm 4,4748\right.$ Log UFC. $\left.\mathrm{mL}^{-1}\right)$ quanto comparados aos tratamentos com $\mathrm{Mo}_{0,10 \%}\left(4,81 \pm 3,40\right.$ Log UFC. $\left.\mathrm{mL}^{-1}\right), \mathrm{Mo}_{0,15 \%}\left(4,62 \pm 3,27\right.$ Log UFC. $\mathrm{mL}^{-}$ $\left.{ }^{1}\right)$ e $\mathrm{Mo}_{0,20 \%}\left(4,53 \pm 3,20 \mathrm{Log} \mathrm{UFC} \cdot \mathrm{mL}^{-1}\right)$. A maior redução microbiana foi

\footnotetext{
Referência:

Carolini Esmeriz da Rosa, João Paulo Gomes de Sousa, Fernanda Guimarães Jeronimo, Ed Carlo Rosa Paiva, Jupyracyara Jandyra de Carvalho Barros. Emprego de Moringa Oleifera Lam Na Inibição de Staphylococcus aureus ATCC 25923 Cultivado em Derivado Lácteo Sintético. In: Anais do 12을 Congresso Latinoamericano de Microbiologia e Higiene de Alimentos - MICROAL 2014 [= Blucher Food Science Proceedings, num.1, vol.1]. São Paulo: Editora Blucher, 2014. 
observada em T8 $\left(\mathrm{Mo}_{0,20 \%}: 3,00 \pm 2,12 \mathrm{Log}\right.$ UFC. $\left.\mathrm{mL}^{-1}\right)$. Foi observada estabilidade da atividade antimicrobiana até 12 horas para $\mathrm{Mo}_{0,20 \%}$, com redução de aproximadamente $26 \%$ do micro-organismo quando comparado ao grupo controle no mesmo período. Uma possibilidade para maior redução desse micro-organismo teste seria o aumento das concentrações do extrato, tomando-se a preocupação para não afetar as propriedades sensoriais do alimento. Os resultados obtidos nesta pesquisa são dados preliminares à aplicação do M. oleifera como bioconservante, devendo haver outros ensaios para avaliar sua ação in situ.

Palavras-Chave: Moringa oleifera, derivado lácteo, qualidade sanitária Agência de Fomento: 